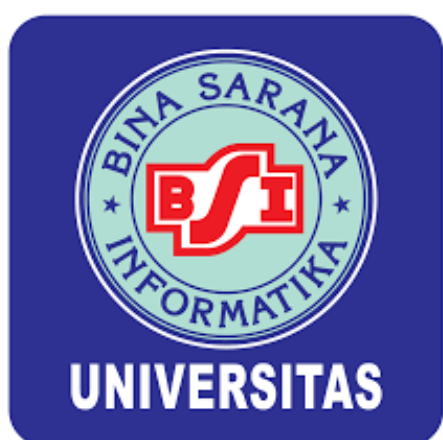

Ukuran Gejala Pusat Data Belum Di Kelompokkan Dari Sampel Data Jumlah Anggota DPRD Menurut Fraksi Kab. Tangerang (2013) Berdasarkan Jenis Kelamin Laki-laki
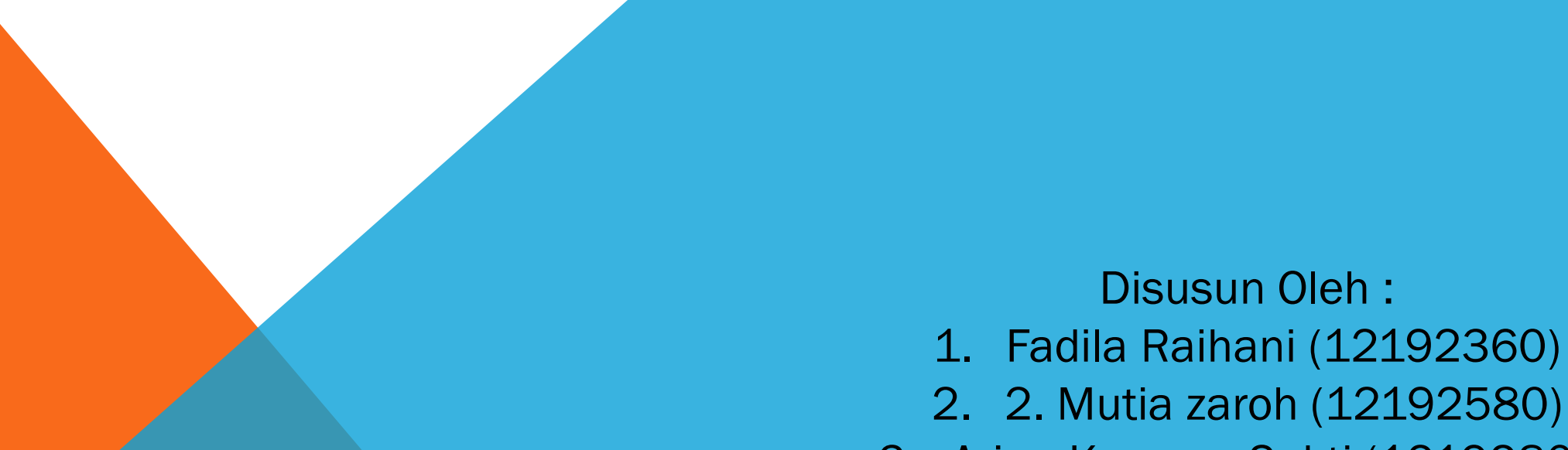

3. Arjun Kusuma Sakti (12192804) 


\section{PENGERTIAN UKURAN GEJALA PUSAT DATA BELUM DIKELOMPOKKAN}

Ukuran gejala pusat data belum dikelompokan adalah data yang tidak disusun ke dalam distribusi frekuensi sehingga tidak mempunyai interval kelas dan titik tengah kelas. Sedangkan pada Ukuran gejala pusat data dikelompokkan, datanya sudah disusun ke dalam sebuah distribusi frekuensi sehingga data tersebut mempunyai interval kelas yang jelas dan mempunyai titik tengah kelas.

Ada beberapa macam ukuran gejala pusat data belum dikelompokan yaitu rata-rata hitung(mean), rata-rata ukur/geometri, rata-rata harmonis, rata-rata tertimbang, median, modus, dan fraktil ( kuartil, desil dan persentil). 
SAMPEL DATA JUMLAH ANGGOTA DPRD MENURUT FRAKSI KAB. TANGERANG (2013)

Dalam penulisan jurnal kali ini, sampel data yang di ambil yaitu mengenai Jumlah Anggota DPRD Menurut Fraksi di Kabupaten Tangerang (2013). Dengan sampel data tersebut, kita akan mencari Mean, Rata-rata Ukur(Geometri), Rata-rata Harmonis, Median, Modus, Kuartil, Desil dan Persentil.
Adapun table data yang akan dijadikan sampel adalah sebagai berikut:

\begin{tabular}{|l|l|l|l|l|}
\hline No & \multicolumn{1}{|c|}{ Fraksi } & \multicolumn{1}{|c|}{ Pria } & Wanita & Total \\
\hline 1 & Partai Demokrat & 8 & 1 & 9 \\
\hline 2 & Partai Golkar & 7 & 1 & 8 \\
\hline 3 & PDI Perjuangan & 5 & 1 & 6 \\
\hline 4 & PKS & 4 & 0 & 4 \\
\hline 5 & Partai Hanura & 5 & 2 & 7 \\
\hline 6 & Partai Gerindra & 4 & 0 & 4 \\
\hline 7 & PPP & 4 & 0 & 4 \\
\hline 8 & Amanat Bangsa & 4 & 0 & 4 \\
\hline 9 & BPU & 4 & 0 & 4 \\
\hline Jumlah & & 45 & 5 & 50 \\
\hline
\end{tabular}




\section{A. MEAN}

Istilah mean dikenal dengan sebutan angka rata-rata. Ratarata hitung (mean) adalah nilai yang mewakili sekelompok data. Mean diperoleh dengan cara menjumlahkan semua data yang ada dibagi dengan banyaknya data

untuk rata-rata populasi:

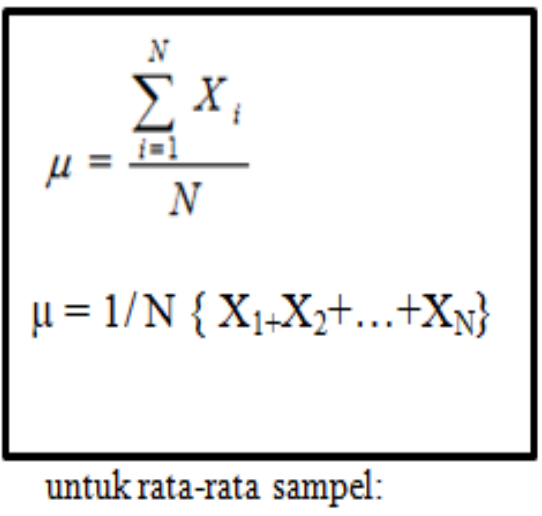

$$
\begin{aligned}
& \bar{X}=\frac{\sum_{i=1}^{n} X_{i}}{n} \\
& \bar{X}=1 / n\left\{X_{1}+X_{2}+\ldots+X_{n}\right\}
\end{aligned}
$$

Keterangan :

$\Sigma=$ lambang penjumlahan semua gugus data pengamatan

$\mathrm{X}_{\mathrm{i}}=$ Nilai datake- $\mathrm{i}$

$\mathrm{n}=$ banyaknya sampel data

$\mathrm{N}=$ banyaknya data populasi

$\bar{X}=$ nilai rata-rata sampel

$\mu=$ nilai rata-rata populasi 
Sampel Data : 8,7,5,4,5,4,4,4,4

$$
\begin{aligned}
& \mathcal{X}=\frac{1}{n}(\mathcal{X} 1+\mathcal{X} 2+\mathcal{X} 3+\mathcal{X} 4+\mathcal{X} 5 \ldots+\mathcal{X} 9) \\
& \mathcal{X}=\frac{1}{9}(4+4+4+4+4+5+5+7+8) \\
& \mathcal{X}=\frac{1}{9} \times 45 \\
& \mathcal{X}=5
\end{aligned}
$$

Jadi, rata-rata hitung yang diperoleh dari sampel data Fraksi Anggota DPRD berdasarkan jenis kelamin pria adalah 5 . 


\section{B. RATA-RATA UKUR (GEOMETRI)}

Rata-rata ukur (geometri) adalah rata-rata yang Rumus Rata-rata ukur (geometri) : diperoleh dengan $\mathrm{G}=\sqrt[i]{\mathrm{X} 1 . \mathrm{X} 2 \ldots \mathrm{Xn}}$ atau mengalikan semua data dalam suatu kelompok $\log \mathrm{G}=\left(\sum \log \mathrm{X}_{\mathrm{i}}\right) / \mathrm{n}$ sampel, kemudian diakarpangkatkan dengan banyaknya data sampel tersebut. 
CONTOH MENGHITUNG RATA-RATA UKUR (GEOMETRI) DARI DATA JUMLAH ANGGOTA DPRD FRAKSI KAB. TANGERANG (2013)

Rumus Rata-rata ukur (geometri) :

$$
\begin{aligned}
& \mathrm{G}=\sqrt{\mathrm{X} 1 . \mathrm{X} 2 \ldots \mathrm{Xn}} \text { atau } \\
& \log \mathrm{G}=\left(\sum \log \mathrm{X}_{\mathrm{i}}\right) / \mathrm{n} \\
& G=n \sqrt{X 1+X 2+X 3+X 4 \ldots+X 9} \\
& G=9 \sqrt{4.4 .4 .4 .4 .5 .5 .7 .8} \\
& G=9 \sqrt{1.433 .600} \\
& G=159.288
\end{aligned}
$$

Maka, rata-rata ukur(geometri) yang di dapat adalah 159.288 


\section{RATA-RATA HARMONIS}

\section{Rumus rata-rata}

Harmonis

$$
\mathrm{R}_{\mathrm{h}}=\frac{n}{\sum \frac{1}{x i}}
$$

Rata-rata harmonis adalah ratarata yang dihitung dengan cara mengubah semua data menjadi pecahan, dimana nilai data dijadikan sebagai penyebut dan pembilangnya adalah satu, kemudian semua pecahan tersebut dijumlahkan dan selanjutnya dijadikan sebagai pembagi jumlah data. Rata-rata harmonik sering disebut juga dengan kebalikan dari Rata-rata Hitung (mean). 
CONTOH MENGHITUNG RATA-RATA HARMONIS DARI DATA JUMLAH

ANGGOTA DPRD FRAKSI KAB. TANGERANG (2013)

$$
\begin{aligned}
R h & =\frac{\frac{1}{4}+\frac{1}{4}+\frac{1}{4}+\frac{1}{4}+\frac{1}{4}}{R h}=\frac{9}{\frac{5}{4}+\frac{2}{5}+\frac{1}{7}+\frac{1}{8}} \\
R h & =\frac{9}{\frac{350+112+40+35}{280}} \\
R h & =\frac{9}{\frac{537}{280}} \\
R h & =\frac{537}{280} \times \frac{1}{9} \\
& =\frac{537}{2520} \\
& =\frac{357: 3}{2520: 3} \\
& =\frac{179}{840}
\end{aligned}
$$

Data yang belum diurutkan :

$8,7,5,4,5,4,4,4,4$

Data yang telah diurutkan :

$4,4,4,4,4,5,5,7,8$

Jumlah Data : 9 


\section{RATA-RATA TERTIMBANG}

Rata-rata

tertimbang/terbobot adalah rata-rata yang dihitung dengan memperhitungkan timbangan/bobot untuk setiap datanya. Setiap penimbang/bobot tersebut merupakan pasangan setiap data.

Rumus Rata-rata

Tertimbang

$\bar{X}=\frac{\sum X i . W i}{\sum W i}$

Keterangan:

$X=$ rata-rata tertimbang

$\mathrm{Xi}=$ nilai data ke-i

$\mathrm{Wi}=$ bobot data ke-i 


\section{CONTOH MENGHITUNG RATA-RATA TERTIMBANG DARI DATA JUMLAH ANGGOTA DPRD FRAKSI KAB. TANGERANG (2013)}

Jumlah fraksi laki-laki (Xi)

tertimbang dengan total jumlah

fraksi menurut jenis kelamin(Wi)

$X 1=8, X 2=7, X 3=5, X 4=4, X 5=$

$5, X 6=4, X 7=4, X 8=4, X 9=4$

$\mathrm{W} 1=9, \mathrm{~W} 2=8, \mathrm{~W} 3=6, \mathrm{~W} 4=4$, $\mathrm{W} 5=7, \mathrm{~W} 6=4, \mathrm{~W} 6=4, \mathrm{~W} 7=4$, $\mathrm{W} 8=4, \mathrm{~W} 9=4$

$$
\begin{aligned}
X & =\frac{\Sigma X i \cdot W i}{\Sigma W i} \\
& =\frac{(X 1 . W 1)+(X 2 . W 2)+(X 3 . W 3)+(X 4 . W 4) \ldots+(X 9 . W 9)}{W 1+W 2+W 3+W 4 \ldots+W 9}
\end{aligned}
$$$$
=\frac{(8 \times 9)+(7 \times 8)+(5 \times 6)+(4 \times 4)+(5 \times 7)+(4 \times 4)+(4 \times 4)+(4 \times 4)+(4 \times 4)}{9+8+6+4+7+4+4+4+4}
$$$$
=\frac{72+56+30+16+35+16+16+16+16}{50}
$$$$
=\frac{273}{50}
$$$$
=5.46
$$ 


\section{E. MEDIAN}

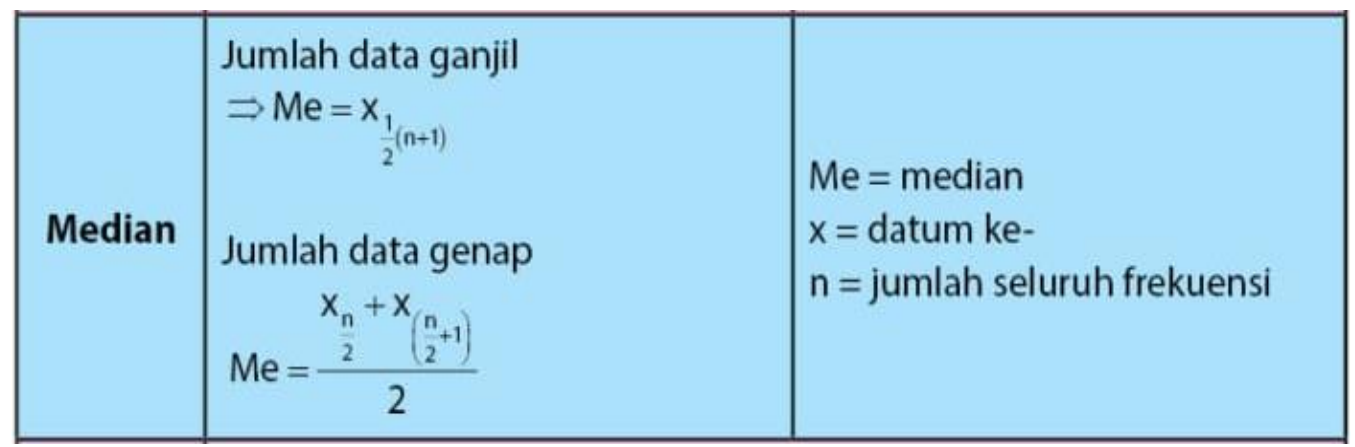

Median merupakan suatu nilai yang berada di tengah-tengah data, setelah data tersebut diurutkan. Atau dengan kata lain, median adalah titik tengah dari semua nilai data yang telah diurutkan dari nilai yang terkecil ke yang terbesar, atau sebaliknya dari yang terbesar ke yang terkecil. Hasil median sama dengan hasil dari kuartil kedua.

Posisi tengah dari seperangkat data sebanyak $\mathrm{N}$ yang telah terurut terletak pada posisi yang ke $(\mathrm{N}+1) / 2$. 
CONTOH MENGHITUNG MEDIAN DARI DATA JUMLAH ANGGOTA DPRD FRAKSI KAB. TANGERANG (2013)

\section{Median}

Data ganjil $: n=9$

$$
\begin{aligned}
\text { Me } & =\frac{\mathcal{X}(n+1)}{2} \\
& =\frac{\mathcal{X}(9+1)}{2} \\
& =\frac{\mathcal{X}(10)}{2} \\
& =5
\end{aligned}
$$

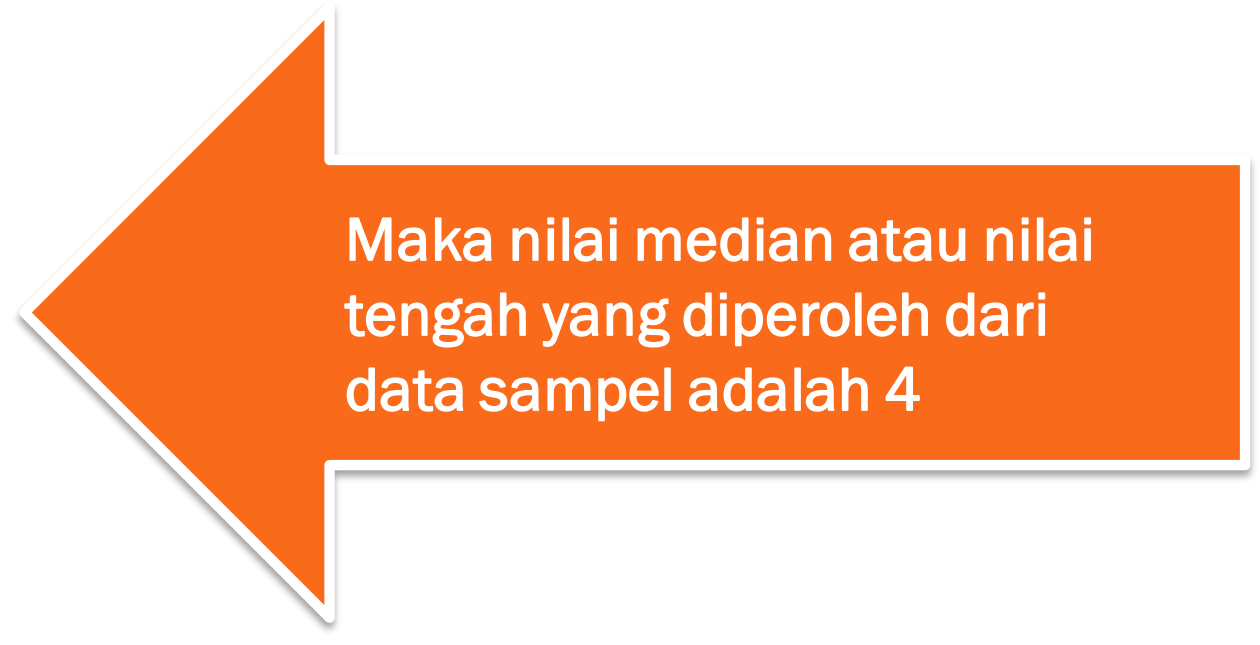

$\mathcal{X} 5=4$ 


\section{F. MODUS}

Modus adalah nilai yang paling sering muncul dari serangkaian data atau yang mempunyai frekuensi paling tinggi.
Data yang belum diurutkan : $8,7,5,4,5,4,4,4,4$

Data yang telah diurutkan :

$4,4,4,4,4,5,5,7,8$

Modus : 4 


\section{G. KUARTIL}

\begin{tabular}{|l|c|}
\hline Jenis Kuartil & $\begin{array}{c}\text { Rumus Kuartil } \\
\text { Data Tunggal }\end{array}$ \\
\hline Kuartil Bawah & $\mathrm{Q}_{1}=\mathrm{x}_{\frac{1}{4^{(n+1)}}}$ \\
\hline Kuartil Tengah & $\begin{array}{c}\mathrm{Q}_{2}=\mathrm{x}_{\frac{1}{2}} \\
\text { Kn+1) }\end{array}$ \\
\hline Kuartil Atas & $\mathrm{Q}_{3}=\mathrm{x}_{\frac{3}{4}}$ \\
\hline
\end{tabular}

Pada prinsipnya, pengertian kuartil sama dengan median. Perbedaanya hanya terletak pada banyaknya pembagian kelompok data. Median membagi kelompok data atas 2 bagian, sedangkan kuartil membagi kelompok data atas 4 bagian yang sama besar, sehingga akan terdapat 3 kuartil yaitu kuartil ke-1, kuartil ke-2 dan kuartil ke-3, dimana kuartil ke-2 sama dengan median. 


\section{CONTOH MENGHITUNG KUARTIL DARI DATA JUMLAH ANGGOTA DPRD FRAKSI KAB. TANGERANG (2013)}

a. Kuartil 1

$$
\begin{aligned}
\operatorname{Letak} \mathrm{Q} 1 & =\frac{i(n+1)}{4} \\
\mathrm{Q} 1 & =\frac{1(9+1)}{4} \\
& =\frac{1(10)}{4} \\
& =\frac{10}{4} \\
& =2.25
\end{aligned}
$$

$$
\begin{aligned}
\mathrm{Q} 1 & =\mathcal{X} 2+0.25(\mathcal{X} 3-\mathcal{X} 2) \\
\mathrm{Q} 1 & =4+0.25(4-4) \\
& =4+0.25(0) \\
& =4
\end{aligned}
$$

b. Kuartil 3

$$
\begin{aligned}
\text { Letak Q3 } & =\frac{i(n+1)}{4} \\
\mathrm{Q} 3 & =\frac{3(9+1)}{4} \\
& =\frac{3(10)}{4} \\
& =\frac{30}{4} \\
& =7.5
\end{aligned}
$$

$$
\begin{aligned}
\mathrm{Q} 3 & =\mathcal{X} 7+0.5(\mathcal{X} 8-\mathcal{X} 7) \\
\mathrm{Q} 3 & =5+0.5(7-5) \\
& =5+0.5(2) \\
& =5+1 \\
& =6
\end{aligned}
$$

\section{Data yang telah diurutkan : 4,4,4,4,4,5,5, 7,8}

Dapat disimpulkan bahwa Q1 yaitu mendapatkan hasil 4 dan yang termasuk data ke-4 dari data terurut yaitu terdapat pada angka 4.
Dapat disimpulkan bahwa Q3 yaitu mendapatkan hasil 6 dan yang termasuk data ke- 6 dari data terurut yaitu terdapat pada angka 5 


\section{H. DESIL}

Desil adalah suatu rangkaian data yang membagi suatu distribusi menjadi 10 bagian yang sama besar.

$\mathrm{Di}=$ nilai yang $\mathrm{ke}(\mathrm{n}+1) / 10, \mathrm{i}=1,2, \ldots, 9$
CONTOH MENGHITUNG DESIL DARI DATA JUMLAH ANGGOTA DPRD FRAKSI KAB. TANGERANG (2013)

$\mathcal{L}$ etak $\mathcal{D} i=\frac{i(n+1)}{10}$

Keterangan:

$D i=$ Desilke $i$

$n=$ Banyaknya data

Misal : tentukan desil ke 5

$$
\begin{aligned}
\text { Letak Di } & =\frac{i(n+1)}{10} \\
& =\frac{5(9+1)}{10} \\
& =\frac{5(10)}{10} \\
& =\frac{50}{10} \\
& =5
\end{aligned}
$$




\section{PERSENTIL}

Persentil adalah ukuran letak yang membagi suatu distribusi menjadi 100 bagian yang sama besar.

Adapun rumus menhitung Persentil adalah sebagai berikut

$\mathrm{Pi}_{1}=$ nillai yangke $\mathrm{i}(\mathrm{n}+1) / 100, \mathrm{i}=1,2, \ldots, 99$
CONTOH MENHITUNG PERSENTIL DARI DATA JUMLAH ANGGOTA DPRD FRAKSI KAB. TANGERANG (2013)

Rumus: $P i=\frac{i(n+1)}{100}$

Misal : Mencari persentil ke 15

$$
\begin{aligned}
P 15 & =\frac{15(9+1)}{100} \\
& =\frac{15(10)}{100} \\
& =\frac{150}{100} \\
& =1.5 \\
P 15 & =\mathcal{X} 1+0.5(\mathcal{X} 2-\mathcal{X} 1) \\
& =4+0.5(4-4) \\
& =4+0.5(0) \\
& =4
\end{aligned}
$$


Beberapa langkah yang dapat dilakukan dalam melakukan analysis data statistik adalah sebagai berikut :

1. Dari menu utama Microsoft Excel klik menu Data dan pilih menu Data Analysis.

2. Pilih menu Descriptive Statistics lalu klik OK.

3. Klik button pada Input Range dan masukkan data batas atas kelas kedalam kolom Input Range dengan cara mem-blok data tersebut.

4. Klik button Output Range dan tempatkan pointer pada tempat yang kosong.

5. Pilih Summary Statitstics dan klik ok. 
잉 Outsut 윔 Log

日一逐 Descriptives

fis Tita

B Notes

in Active Dasast 国 Descriptive Statistice

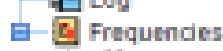

+8 Titis

Notes

WD Active Dahast

Co Statistics

10 Pria

64. Histogram

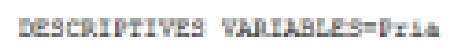

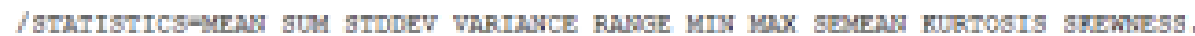

\section{Descriptives}

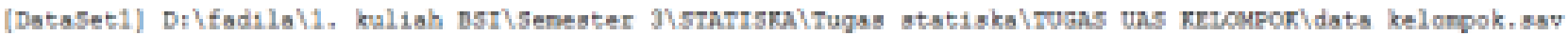

\begin{tabular}{|c|c|c|c|c|c|c|c|c|c|c|c|c|c|}
\hline \multicolumn{14}{|c|}{ Descriethe Staristics } \\
\hline & $\mathrm{N}$ & Range & Minimum & Mzsimum & $8 u m$ & \multicolumn{2}{|c|}{ Mean } & Std. Deviation & Variance & \multicolumn{2}{|c|}{ Skownass } & \multicolumn{2}{|c|}{ Kuntosis } \\
\hline & Statsit & Statsit & Statstc & Statstc & Statistc & Statistic & std. Enroe & Statistic & Statistc & Statistc & Sid. Error & staisit & sta. Em \\
\hline Pria & 9 & 4 & 4 & 8 & 45 & 5,00 & .500 & 1,580 & 2,250 & 1,429 & .717 & 825 & 1,4 \\
\hline valis $\mathrm{N}$ (jistwise) & 9 & & & & & & & & & & & & \\
\hline
\end{tabular}

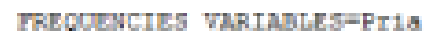

hrties=4

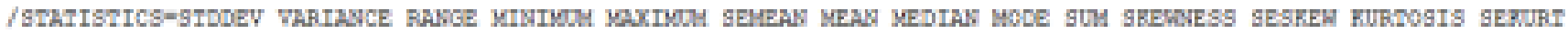

/117570GNose

/CODER=LLALYSIS.

\section{$\rightarrow$ Frequencies}

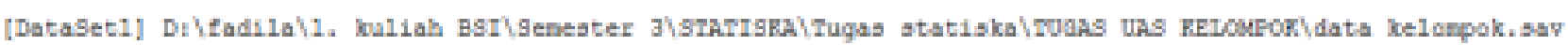




\section{KESIMPULAN}

Dari penjelasan di atas maka dapat disimpulkan bahwa Ukuran Gejala Pusat adalah nilai dalam suatu rangkaian data yang dapat mewakili rangkaian data tersebut. Sedangkan Ukuran Gejala Pusat Data Belum Dikelompokkan adalah data yang tidak disusun ke dalam distribusi frekuensi sehingga tidak mempunyai interval kelas dan titik tengah kelas, mencakup penyajian rata - rata, median, modus, kuartil, desil dan persentil. 
TERIMAKASIH ATAS PERHATIAN NYA 